\title{
FluorMODgui V3.0: A graphic user interface for the spectral simulation of leaf and canopy chlorophyll fluorescence ${ }^{\text {ts }}$
}

\author{
P.J. Zarco-Tejada ${ }^{\mathrm{a}, *}$, J.R. Miller ${ }^{\mathrm{b}}$, R. Pedrós ${ }^{\mathrm{c}}$, W. Verhoef ${ }^{\mathrm{d}}$, M. Berger ${ }^{\mathrm{e}}$ \\ ${ }^{a}$ Consejo Superior de Investigaciones Cientificas (IAS-CSIC), Apdo. de Correos 4084, 14080 - Córdoba, Spain \\ ${ }^{\mathrm{b}}$ Department of Earth and Space Science and Engineering, York University, Toronto, Canada \\ ${ }^{\mathrm{c}}$ Laboratoire Environnement et Développement, Universite Paris 7, Paris, France \\ ${ }^{\mathrm{d}}$ National Aerospace Laboratory NLR, Emmeloord, The Netherlands \\ ${ }^{\mathrm{e}}$ European Space Agency, ESA-ESTEC, Noordwijk, The Netherlands
}

Received 2 February 2005; received in revised form 26 July 2005; accepted 19 August 2005

\begin{abstract}
The FluorMODgui Graphic User Interface (GUI) software package developed within the frame of the FluorMOD project Development of a Vegetation Fluorescence Canopy Model is presented in this manuscript. The FluorMOD project was launched in 2002 by the European Space Agency (ESA) to advance the science of vegetation fluorescence simulation through the development and integration of leaf and canopy fluorescence models based on physical methods. The design of airborne or space missions dedicated to the measurement of solar-induced chlorophyll fluorescence using remote-sensing instruments require physical methods for quantitative feasibility analysis and sensor specification studies. The FluorMODgui model developed as part of this project is designed to simulate the effects of chlorophyll fluorescence at leaf and canopy levels using atmospheric inputs, running the leaf model, FluorMODleaf, and the canopy model, FluorSAIL, independently, through a coupling scheme, and by a multiple iteration protocol to simulate changes in the viewing geometry and atmospheric characteristics. Inputs for the FluorMODleaf model are the number of leaf layers, chlorophyll $a+b$ content, water equivalent thickness, dry matter content, fluorescence quantum efficiency, temperature, species type, and stoichiometry. Inputs for the FluorSAIL canopy model are a MODTRAN-4 6-parameter spectra or measured direct horizontal irradiance and diffuse irradiance spectra, a soil reflectance spectrum, leaf reflectance $\&$ transmittance spectra and a excitation-fluorescence response matrix in upward and downward directions (all from FluorMODleaf), 2 PAR-dependent coefficients for the fluorescence response to light level, relative azimuth angle and viewing zenith angle, canopy leaf area index, leaf inclination distribution function, and a hot spot parameter. Outputs available in the $400-1000 \mathrm{~nm}$ spectral range from the graphical user interface, FluorMODgui, are the leaf spectral reflectance and transmittance, and the canopy reflectance, with and without fluorescence effects. In addition, solar and sky irradiance on the ground, radiance with and without fluorescence on the ground, and topof-atmosphere (TOA) radiances for bare soil and surroundings same as target are also produced. The models and documentation regarding the FluorMOD project can be downloaded at http://www.ias.csic.es/fluormod.
\end{abstract}

(C) 2005 Elsevier Ltd. All rights reserved.

Keywords: Leaf fluorescence; Canopy fluorescence; Graphic user interface; Reflectance; FluorMOD

\footnotetext{
${ }^{25}$ Code available from server at http://www.ias.csic.es/fluormod.

*Corresponding author. Tel.: + $34957499280,+34676954937$; fax: + 34957499252.

E-mail address: pzarco@ias.csic.es (P.J. Zarco-Tejada).

URL: http://www.ias.csic.es/pzarco, http://www.ias.csic.es/fluormod.
} 


\section{Introduction}

The FluorMOD project "Development of a Vegetation Fluorescence Canopy Model" was launched in 2002 by the European Space Agency (ESA) to advance the science of vegetation fluorescence simulation (Miller et al., 2004). The main objective of the project was the development and integration of leaf and canopy fluorescence models based on physical methods. The development of a linked leaf-canopy model to simulate the effects of natural solar-induced fluorescence on canopy-level fluorescence signal may contribute to the assessment of fluorescence detection potential using nearcontact, airborne and satellite-level remote-sensing sensors. Previous results indicate that fluorescence effects are detectable on reflectance signatures at the leaf level (Zarco-Tejada et al., 2000), and at canopy level using airborne hyperspectral sensors (Maier et al., 2003; Zarco-Tejada et al., 2003). As a result of these efforts, the FluorMOD project (Miller et al., 2004) made progress on the development of a leaf model that simulates the effects of chlorophyll fluorescence, FluorMODleaf (Pedrós et al., 2005), and a canopy model, FluorSAIL (Verhoef, 2005), which incorporates an excitation-fluorescence matrix computed externally by means of the leaf-level fluorescence model to simulate the fluorescence effects on the canopy signature. Both models were conveniently linked through FluorMODgui.

The FluorMODleaf model developed within the frame of this project is designed to simulate the chlorophyll fluorescence effects on leaf reflectance and transmittance, based on the widely used and validated PROSPECT leaf optical properties model (Jacquemoud and Baret, 1990). FluorMODleaf is the natural continuation of other previous approaches developed to simulate chlorophyll fluorescence effects on apparent reflectance at the leaf level, such as the Fluorescence-Reflectance-Transmittance model FRT (Zarco-Tejada et al., 2000), and the Stochastic model for Leaf Optical Properties (Maier et al., 1999; Maier, 2000). The new FluorMODleaf model is an adaptation of PROSPECT and is based on radiative transfer theory to accurately simulate the hemispherical reflectance and transmittance of various plant leaves, such as monocots, dicots or senescent leaves, over the solar spectrum. The leaf is characterized with only four input parameters, such as the leaf structure parameter that represents the number of compact layers specifying the average number of air/cell walls interfaces within the mesophyll, the chlorophyll $a+b$ concentration, the equivalent water thickness, and the dry matter content. The fluorescence emission is introduced into PROSPECT, representing the simulated fluxes within the leaf as a network. The core of the model is the fluorescence emission elementary spectrum, a combination of Photosystem I (PSI) and Photosystem II (PSII) fluorescence spectra. Additional input parameters are the fluorescence quantum efficiency, the relative contribution of the two photosystems, stoichiometry of the PSII to PSI reaction centers, leaf temperature, and the light level. Using the flux network diagram, the elementary spectrum is re-absorbed within the leaf, therefore the upward and downward fluorescence spectrum can be described for different wavelengths of excitation.

The second part of FLuorMODgui, the FluorSAIL canopy model, was developed to simulate the chlorophyll fluorescence effects on canopy reflectance using inputs from the FluorMODleaf model. FluorSAIL is based on the SAIL model (Verhoef, 1984) a widely used and validated canopy reflectance model, providing detailed internal radiation profiles at $1 \mathrm{~nm}$ resolution using MODTRAN-4derived solar and sky irradiance data as input. The excitation-fluorescence matrix computed by FluorMODleaf along with the internal radiation profiles simulated for solar and diffuse fluxes are used to calculate the radiance of each leaf. Numerical integration is used to predict the top-of-canopy radiance caused by contributions due to scattering and fluorescence. A photosynthetic active radiation (PAR) light-level fluorescence dependence is applied to individual leaves depending on their depth and their orientation with respect to the sun. In addition, distinction is made between sunlit and shaded leaves by employing the gap probability function of SAIL. The output of FluorSAIL can be used to obtain realistic top-of-canopy as well as and top-of-atmosphere (TOA) radiance contributions associated with solar-induced fluorescence.

The FluorMODgui V3.0 Graphic User Interface (GUI) presented here provides a seamless link between inputs and outputs required for running both FluorMODleaf and FluorSAIL models, facilitating consistent user interaction and enabling the setup of multiple runs to simulate diurnal effects under different viewing geometries. This manuscript provides a description of the graphic interface that will be used as a tool for leaf and canopy model validation through the use of existing and future 
field datasets in the context of this ESA project and the interested scientific community. This interface developed under the FluorMOD project can facilitate the testing of various remote-sensing detection scenarios for future airborne and spaceborne fluorescence missions.

\section{Graphic user interface for the linked leaf-canopy fluorescence model}

The FluorMOD Graphic User Interface presented here (FluorMODgui V3.0) is developed in Visual Studio .net framework with Visual Basic code (Microsoft, Redmond, WA, USA) compiled into an executable file to run under Microsoft Windows XP operating system. A general view of the GUI can be seen in Fig. 1, showing four main parts: (i) Menu Area for full control of the interface; (ii) Irradiance File and PAR Dependence input area; (iii) Leaf Model Area for inputs and graphic outputs to run the FluorMODleaf model; and (iv)
Canopy Model Area for inputs and graphic outputs to run the FluorSAIL model.

The Menu Area for full control of the interface enables the running of the leaf model or canopy model independently, or both linked together in a single run. In addition, both leaf and canopy models can be executed through a Diurnal and Iteration Tool to simulate the diurnal effects of a changing viewing geometry, atmospheric characteristics, and typical leaf temperature variations along the course of a day. The Multiple Iteration Execution option enables the execution of the models iterating a selected leaf or canopy variable as in batch processes. Other options in the Menu Area are tools for the user such as opening the working directory where all input and output files are stored, providing help buttons for the leaf and canopy models and GUI interface.

The Irradiance File and PAR Dependence input area is comprised of two subsections, one for the PAR dependence parameters, and another for the Irradiance File Selection with a text window for

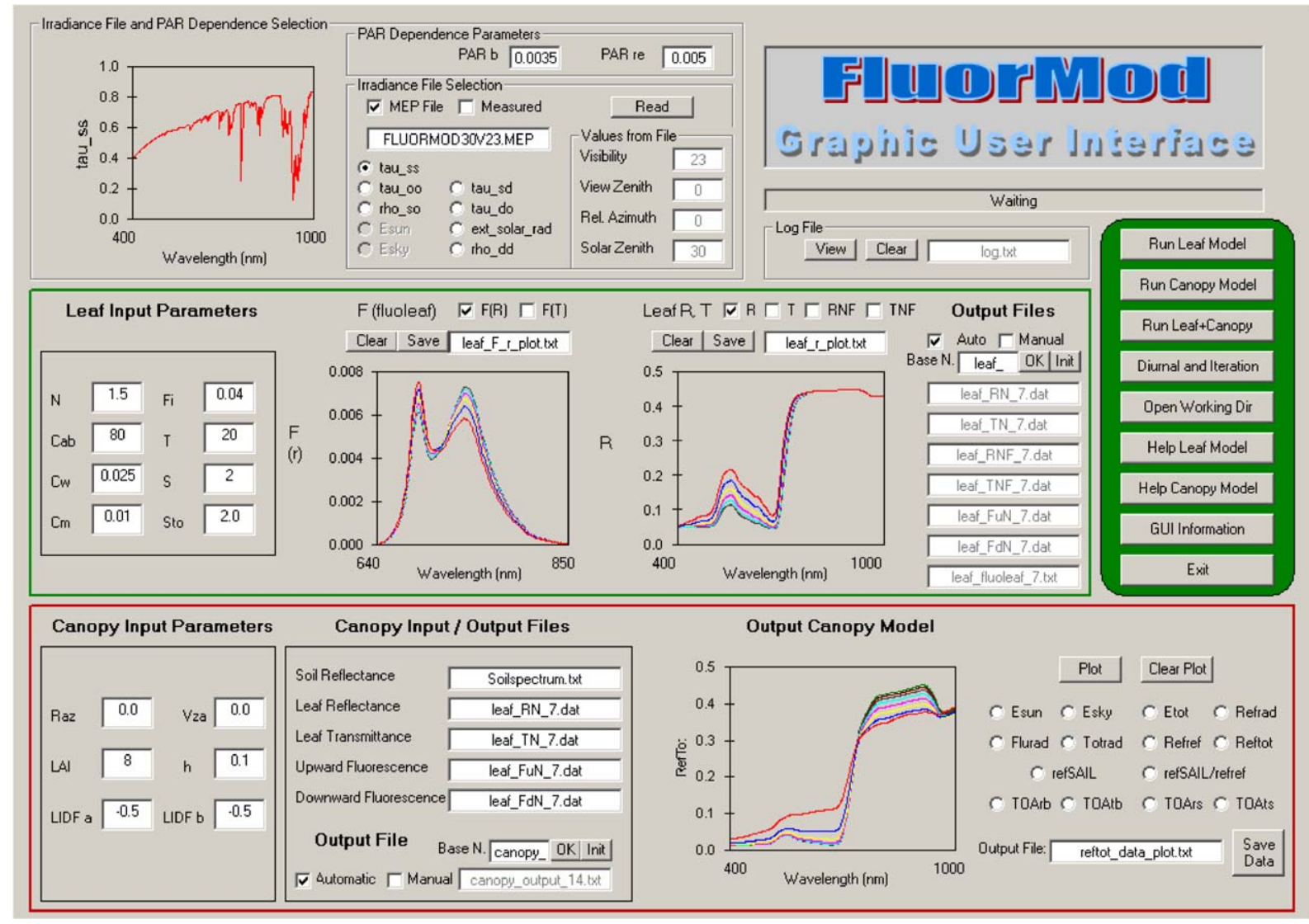

Fig. 1. General view of FluorMOD graphic user interface. 
the name of the input irradiance file, with plotting capabilities. This Irradiance File and PAR Dependence input area is common for both the leaf and the canopy-level models.

Other main areas of the Graphic User Interface are (i) the Leaf Model Area and (ii) the Canopy Model Area, designed to enable the specification of leaf and canopy inputs and generation of graphic outputs with plotting capabilities. These two areas of the interface along with the Irradiance File and PAR Dependence input area will be described in detail in the following sections.

The FluorMODgui provides a convenient link between the leaf and canopy models, with proper input/output file naming and data structure. Some of the capabilities incorporated enable error handling on file opening; an automatic and manual output naming system; a base-name input window for a flexible file naming system; help files provided in text form for both the leaf and canopy models; a direct link with the working directory to access input and output files; a status screen showing when the leaf or canopy model is running, disabling execution buttons in such case; graphs with plot capability for multiple series, to enable visualizations of comparisons and trends; data from plots with multiple series can be saved in a single text file for easy comparison between different model runs; a log file viewing button enables loading a text file where all inputs used for running the leaf and canopy model are stored; finally, a pop-up window with contact information for the leaf, canopy model and GUI authors is available.

\subsection{Atmospheric and illumination inputs}

The Irradiance File and PAR Dependence input area (Fig. 2) is comprised of two subsections, one for the PAR dependence parameters, and another for the Irradiance File Selection. The Irradiance File Selection area enables a selection of the irradiance file that will be used in the simulations. If the MEP File option is selected, a MEP file format from MODTRAN-4 (Berk et al., 1999) will be used as input for the simulations, enabling the graphic view of the input file data. The beginning of each MEP file is a copy of the associated so-called ".tp5" file used as input for MODTRAN-4, containing among others the values for visibility, and solar zenith, view zenith and relative azimuth angle. The MEP file contains effective optical parameters in the $400-1000 \mathrm{~nm}$ spectral range such as the direct transmittance in sun direction (tau_ss), direct transmittance in view direction (tau_oo), diffuse transmittance for sunlight (tau_sd), diffuse transmittance in view direction (tau_do), atmospheric path reflectance (rho_so), spherical albedo (rho_dd), and the extraterrestrial radiance of a white horizontal plane (ext_solar_rad) in $\mathrm{mW} \mathrm{cm}{ }^{-2} \mu \mathrm{m}^{-1} \mathrm{sr}^{-1}$.

If the Measured option is selected, simulations will be conducted with collimated (direct solar) irradiance (Esun) and diffuse (sky) irradiance (Esky) measured by the user in $\mathrm{W} \mathrm{m}^{-2} \mu \mathrm{m}^{-1}$. The description of the input parameters for the atmospheric and illumination conditions for FluorMODleaf and FluorSAIL models can be seen in Table 1. Plotting

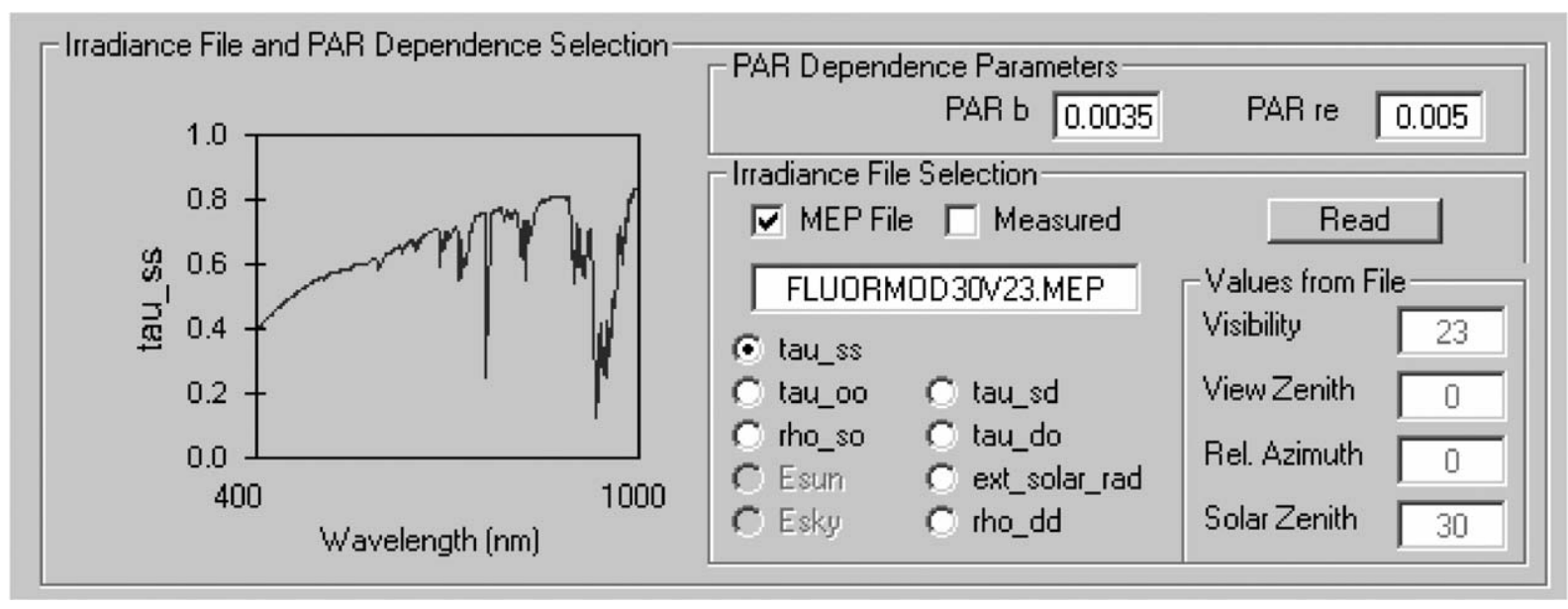

Fig. 2. View of atmospheric file input area of FluorMOD graphic user interface. 
capabilities enable visualization of the MODTRAN-simulated MEP file or the measured illumination file used as input for simulations. In addition, the file header from the MEP or measured irradiance files is read to show the visibility, view zenith, relative azimuth, and solar zenith angles for which the MODTRAN simulated file was produced or the user irradiance file was measured.

The PAR Dependence input area allows input for the electron transport resistance $\left(\mathrm{PAR}_{\mathrm{re}}\right)$ and heat dissipation constant $\left(\mathrm{PAR}_{\mathrm{b}}\right)$, parameter that relates the photosynthetic active radiation with the rate constant for dissipation and the lowest value of this constant for dissipation. The combination of PAR $\mathrm{P}_{\mathrm{re}}$ and $\mathrm{PAR}_{\mathrm{b}}$ parameters is used to relate PAR and fluorescence (Rosema et al., 1998). The $\mathrm{PAR}_{\mathrm{re}}$ and PAR $_{\mathrm{b}}$ parameters are used in FluorMODleaf model to simulate leaf reflectance and transmittance with added fluorescence effects, and in FluorSAIL to generate canopy reflectance with the fluorescence addition.

\subsection{The Fluor MODleaf leaf model interface}

The FluorMODleaf Leaf Model Interface area (Fig. 3) is comprised by (i) a Leaf Input Parameters area; (ii) two graphic outputs with multiple series capability; and (iii) a set of text windows where the output files produced by FluorMODleaf are shown.

The Leaf Input Parameters area requires a total of 8 inputs, such as the number of layers in PROSPECT $(N)$; chlorophyll $a+b$ content in $\mu \mathrm{g} /$ $\mathrm{cm}^{2}\left(C_{a b}\right)$; water equivalent thickness in $\mathrm{cm}\left(C_{\mathrm{w}}\right)$; dry matter content in $\mathrm{g} / \mathrm{cm}^{2}\left(C_{\mathrm{m}}\right)$; fluorescence

Table 1

Input parameters for atmospheric and illumination conditions for FluoMODleaf and FluorSAIL models

\begin{tabular}{|c|c|c|c|}
\hline Parameter & Description & Range & Units \\
\hline MEP File from MODTRAN & Atm. Simulation with MODTRAN & & \\
\hline tau_ss & Direct transmittance in sun direction & - & - \\
\hline tau_oo & Direct transmittance in view direction & - & - \\
\hline tau_sd & Diffuse transmittance for sunlight & - & - \\
\hline tau_do & Diffuse transmittance in view direction & - & - \\
\hline rho_so & Atmospheric path reflectance & - & - \\
\hline rho_dd & Spherical albedo & - & - \\
\hline ext_solar_rad & Extraterrestrial radiance of a white Lambertian horizontal panel & - & $\mathrm{mW} \mathrm{cm}{ }^{-2} \mu \mathrm{m}^{-1} \mathrm{sr}^{-1}$ \\
\hline Measured Irradiance File & Irradiance measurements made & & \\
\hline Esun & Direct solar irradiance at surface & - & $\mathrm{W} \mathrm{m}^{-2} \mu \mathrm{m}^{-1}$ \\
\hline Esky & Diffuse sky irradiance at surface & - & $\mathrm{W} \mathrm{m} \mathrm{m}^{-2} \mu \mathrm{m}^{-1}$ \\
\hline PAR Dependence & PAR dependence parameters & & \\
\hline $\mathrm{PAR}_{\mathrm{re}}$ & Electron transport resistance & $0-1$ & - \\
\hline $\mathrm{PAR}_{b}$ & Heat dissipation constant & $0-1$ & - \\
\hline
\end{tabular}

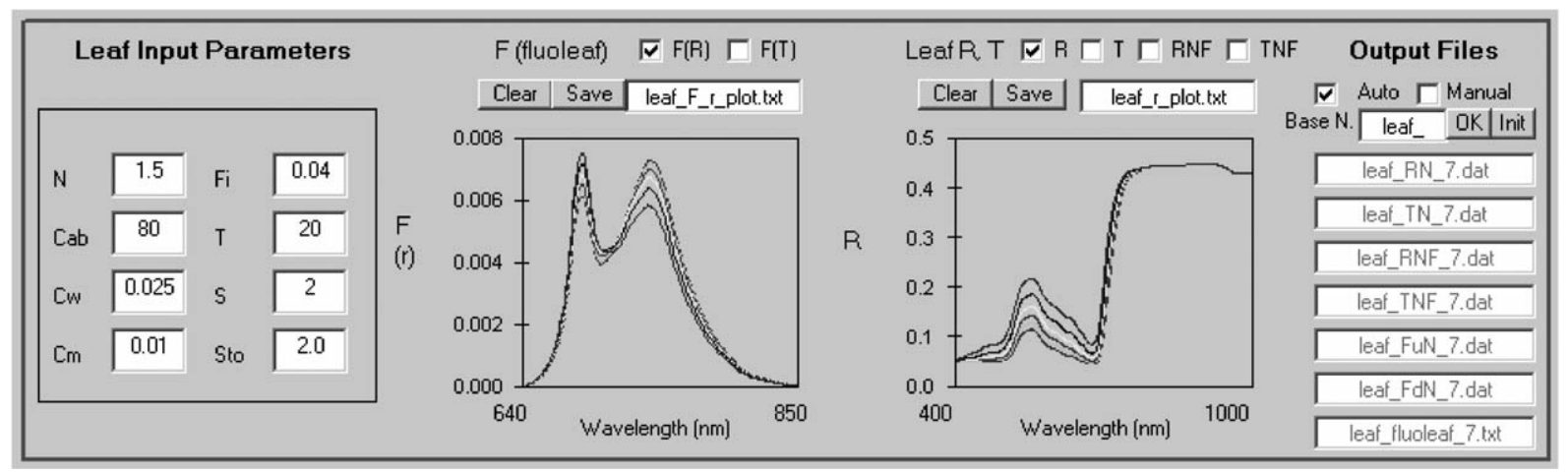

Fig. 3. View of leaf model area of FluorMOD graphic user interface. 
quantum efficiency ( $\mathrm{Fi}$ ), from 0 (no fluorescence) to 0.1 (10\% fluorescence); leaf temperature in degrees Celsius (T); species temperature dependence (S) (after Agati, 1998), with $1=$ broad bean; 2 = bean; 3 = ficus; $4=$ tomato; and $5=$ pea; and stoichiometry of PSII to PSI reaction centers (Sto), which depends on species and light conditions during plant growth, with values for high light around 2 and low light around 1. The inputs for FluoMODleaf fluorescence model are shown in Table 2, also indicating the ranges and units for each parameter considered acceptable according to the model formulation.

The outputs generated after execution of the FluoMODleaf fluorescence model are a set of seven text files containing the leaf reflectance and transmittance without fluorescence ( $\mathrm{RN}$ and $\mathrm{TN}$ ), the

Table 2

Input parameters for FluoMODleaf fluorescence model

\begin{tabular}{llll}
\hline Parameter & Description & Range & Units \\
\hline$N$ & Internal structure & $1-3$ & - \\
& parameter & & \\
$C_{a b}$ & Chlorophyll $a+b$ & $5-100$ & $\mu \mathrm{g} / \mathrm{cm}^{2}$ \\
$C_{\mathrm{w}}$ & Leaf water content & $0-0.05$ & $\mathrm{~cm}$ \\
$C_{\mathrm{m}}$ & Dry matter content & $0.002-0.02$ & $\mathrm{~g} / \mathrm{cm}^{2}$ \\
$F_{\mathrm{i}}$ & Fluorescence & $0-0.1$ & - \\
& quantum efficiency & & \\
$T$ & Temperature & $5-25$ & \\
$S$ & Species temperature & 1 : broad bean; & - \\
& dependence & 2: bean; & \\
& & 3: ficus; & \\
& & 4: tomato; & \\
& & 5: pea & \\
Sto & Stoichiometry of & high light: Sto $~ 2 ;$ & - \\
& PS II to PS I & low light: Sto 1.1 & \\
& &
\end{tabular}

leaf reflectance and transmittance with fluorescence (RNF and TNF) using the PAR parameters to produce the fluorescence emission at the leaf level (fluoleaf), and two matrices ( $\mathrm{FuN}$ and $\mathrm{FdN}$ ), containing the upward and downward fluorescence matrices corresponding to excitation wavelengths in the $400-750 \mathrm{~nm}$ range and fluorescence emission in the $640-850 \mathrm{~nm}$ range. Outputs RN, TN, RNF and TNF are generated for the $400-1000 \mathrm{~nm}$ range at $1 \mathrm{~nm}$ resolution, and fluoleaf fluorescence emission in the $640-850 \mathrm{~nm}$ range at $1 \mathrm{~nm}$ resolution. The outputs of the FluoMODleaf fluorescence model are shown in Table 3 , indicating the spectral ranges and resolution. The output spectral files with the fluorescence emission at the leaf level (fluoleaf) and the reflectance and transmittance with and without the fluorescence emission (RN, TN, RNF and TNF) can be plotted in the leaf model area of the GUI, enabling the displaying of multiple series for comparison purposes. An automatic or manualnaming scheme for the leaf files generated can be selected using a specific base name for each simulation experiment. The graphs with multiple series plotted can be saved in a text file containing the same series displayed on the plot. This capability avoids the need for loading every single output from a set of simulations for a given parameter. Outputs from FluoMODleaf model required as inputs for the FluorSAIL canopy model are automatically updated in the input windows of the FluorSAIL interface area described in the next section.

\subsection{The FluorSAIL canopy model interface}

The FluorSAIL Canopy Model Interface (Fig. 4) is divided into three different areas with (i) the input area for the canopy parameters; (ii) the area for

Table 3

Outputs from FluoMODleaf fluorescence model

\begin{tabular}{lll}
\hline File & Description & Range \\
\hline RN.dat & Leaf reflectance without fluorescence & $400-1000 \mathrm{~nm}$ at $1 \mathrm{~nm}$ resolution \\
TN.dat & Leaf transmittance without fluorescence & $400-1000 \mathrm{~nm}$ at $1 \mathrm{~nm}$ resolution \\
RNF.dat & Leaf reflectance with fluorescence & $400-1000 \mathrm{~nm}$ at $1 \mathrm{~nm}$ resolution \\
TNF.dat & Leaf transmittance with fluorescence & $400-1000 \mathrm{~nm}$ at $1 \mathrm{~nm}$ resolution \\
FuN.dat & Upward fluorescence matrix & Excitation wavelengths in $400-750 \mathrm{~nm}$ range; \\
FdN.dat & Downward fluorescence matrix & fluorescence emission in $640-850 \mathrm{~nm}$ range \\
fluoleaf.txt & Solar induced fluorescence & Excitation wavelengths in $400-750 \mathrm{~nm}$ range; \\
\hline
\end{tabular}




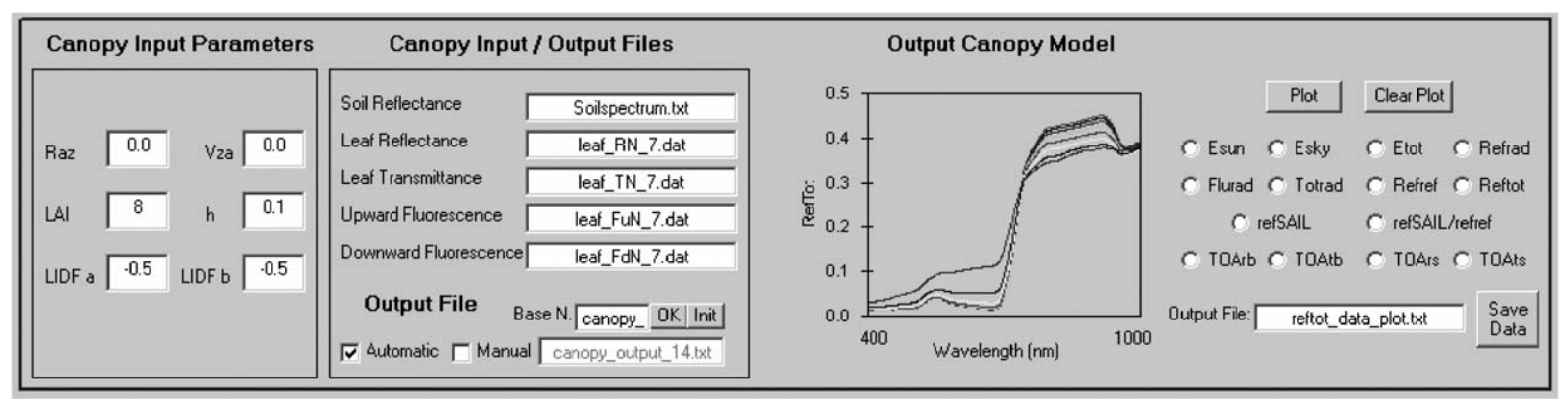

Fig. 4. View of canopy model area of FluorMOD graphic user interface.

Table 4

Input parameters/files for FluorSAIL canopy model

\begin{tabular}{|c|c|c|c|}
\hline Parameter/File & Description & Range & Units \\
\hline Raz & Relative azimuth angle & $0-180$ & Deg \\
\hline Vza & Viewing zenith angle & $0-85$ & Deg \\
\hline LAI & Leaf area index & $0-8$ & - \\
\hline $\mathrm{h}$ & Hot spot size parameter & $0.01-1$ & - \\
\hline $\mathrm{LIDF}_{a} ; \mathrm{LIDF}_{b}$ & Leaf inclination distribution function ${ }^{\mathrm{a}}$ & $\begin{array}{l}\text { spherical }(a=-0.35, b=-0.15) \\
\text { planophile }(a=1, b=0) \\
\text { erectophile }(\mathrm{a}=-1, b=0) \\
\text { plagiophile }(\mathrm{a}=0, b=-1) \\
\text { extremophile }(\mathrm{a}=0, b=1) \\
\text { uniform }(\mathrm{a}=0, b=0)\end{array}$ & \\
\hline soilspectrum.txt & spectral soil reflectance file & $400-1000 \mathrm{~nm}$ at $10 \mathrm{~nm}$ resol. & - \\
\hline RN.dat & $\begin{array}{l}\text { Leaf reflectance without fluorescence in } \\
400-1000 \mathrm{~nm} \text { range }\end{array}$ & $400-1000 \mathrm{~nm}$ at $1 \mathrm{~nm}$ resol. & - \\
\hline TN.dat & $\begin{array}{l}\text { Leaf transmittance without fluorescence in } \\
400-1000 \mathrm{~nm} \text { range }\end{array}$ & $400-1000 \mathrm{~nm}$ at $1 \mathrm{~nm}$ resol. & - \\
\hline FuN.dat & $\begin{array}{l}\text { Upward fluorescence matrix with excitation } \\
\text { and fluorescence emission }\end{array}$ & $\begin{array}{l}\text { Excitation wavelengths in } 400-750 \mathrm{~nm} \text { range } \\
\text { and fluorescence emission in } 640-850 \mathrm{~nm} \\
\text { range }\end{array}$ & - \\
\hline FdN.dat & $\begin{array}{l}\text { Downward fluorescence matrix with } \\
\text { excitation and fluorescence emission }\end{array}$ & $\begin{array}{l}\text { Excitation wavelengths in } 400-750 \mathrm{~nm} \text { range } \\
\text { and fluorescence emission in } 640-850 \mathrm{~nm} \\
\text { range }\end{array}$ & - \\
\hline
\end{tabular}

${ }^{a}$ abs $\left(\operatorname{LIDF}_{a}\right)+\operatorname{abs}\left(\operatorname{LIDF}_{b}\right)<1$ (Verhoef, 1998).

selection of the input spectral files required to run FluorSAIL, as well as the name for the output file generated after execution; and (iii) a plotting area where the generated output file with different spectral variables can be graphed.

The input area for the canopy parameters requires the input for the viewing zenith angle in degrees (Vza), relative azimuth angle in degrees (Raz), the canopy leaf area index (LAI), the hot spot parameter $(h)$, and the leaf inclination distribution function (LIDF) parameters, $\operatorname{LIDF}_{a}$ and $\mathrm{LIDF}_{b}$.

The input spectral files required to run FluorSAIL are the soil spectrum file, and the four output files from the FluorMODleaf model which are inputs for the canopy model, such as the leaf reflectance without fluorescence $(\mathrm{RN})$, leaf transmittance without fluorescence (TN), and the upward $(\mathrm{FuN})$ and downward $(\mathrm{FdN})$ fluorescence matrices. An output file name containing the simulation results is automatically created, using either the automatic naming system or that manually supplied by the user. Table 4 shows the input parameters and spectral files required to run the FluorSAIL canopy model, describing the parameters and ranges.

The output simulation file after FluorSAIL execution contains the solar irradiance in $\mathrm{W} \mathrm{m}^{-2} \mu \mathrm{m}^{-1}$ 
(Esun); sky irradiance in $\mathrm{W} \mathrm{m}^{-2} \mu \mathrm{m}^{-1}$ (Esky); total irradiance in $\mathrm{W} \mathrm{m}^{-2} \mu \mathrm{m}^{-1}$ (Etot); reference ( = without fluorescence) radiance in $\mathrm{W} \mathrm{m}^{-2} \mu \mathrm{m}^{-1} \mathrm{sr}^{-1}$ (refrad); fluorescence radiance in $\mathrm{W} \mathrm{m}^{-2} \mu \mathrm{m}^{-1} \mathrm{sr}^{-1}$ (flurad); total radiance in $\mathrm{W} \mathrm{m}^{-2} \mu \mathrm{m}^{-1} \mathrm{sr}^{-1}$ (totrad); reference reflectance factor (refref); total reflectance factor (including fluorescence) (reftot); reference reflectance factor according to SAIL model (Verhoef, 1984) (refSAIL); ratio SAIL/FluorSAIL for reference reflectance factor (refSAIL/refref); reference top-of-atmosphere radiance for bare soil surroundings in $\mathrm{W} \mathrm{m}^{-2} \mu \mathrm{m}^{-1} \mathrm{sr}^{-1}$ (TOAref bare); total top-of-atmosphere radiance for bare soil surroundings in $\mathrm{W} \mathrm{m}^{-2} \mu \mathrm{m}^{-1} \mathrm{sr}^{-1}$ (TOAtot_bare); reference top-of-atmosphere radiance for surroundings same as target in $\mathrm{W} \mathrm{m}^{-2} \mu \mathrm{m}^{-1} \mathrm{sr}^{-1}$ (TOAref_same); and total top-of-atmosphere radiance for surroundings same as target in $\mathrm{W} \mathrm{m}^{-2} \mu^{-1} \mathrm{sr}^{-1}$ (TOAtot_same) (Table 5).

The plotting area where the generated output file can be graphed enables visualizing any of the 14 spectral parameters generated after FluorSAIL execution. Plotting capabilities permit multiple overlays of several model runs into the same canopy output chart. The data from a single or multiple run for any selected output variable can be saved into a text file that can easily be loaded into spreadsheet software for further data analysis. The output canopy simulation chart plot can be cleared at any time to start a new series of runs, also clearing the output text file created with the simulation results.

\section{Diurnal simulation and multiple iteration tool}

Two objectives adopted by the FluorMOD science team for validating functionality with the FluorMODgui were: (i) to facilitate diurnal simulation of effects on canopy reflectance; and (ii) to accommodate the execution of multiple runs for selected input variables at specified steps. These two objectives are facilitated by the Diurnal Simulation and Multiple Iteration Tool built as a pop-up window that the user can execute from the main menu (Fig. 5). The inputs that the user can modify in the diurnal setup are (i) the illumination file, either as a MEP file or a measured irradiance file; (ii) the leaf-level model variable Temperature $(T)$; and (iii) canopy-level variables such as relative azimuth (Raz) and view zenith angles (Vza). Any of these input variables can be set to a fixed value, or ramped up or down as function of a simulated or real diurnal variation measured by the user in the laboratory or in the field.

The Multiple Iteration Tool enables the selection of a leaf or canopy variable and set the start, end and step increment for a multiple simulation. The multiple run and diurnal execution can be started by first clearing the output plot, or by overlaying new output simulation data to the plot. The multiple simulation tool provides the user with information regarding the number of runs to complete as a function of the start, end and step increments for the given variable, showing the runs left to complete the series of simulations during execution time. The

Table 5

Description of output file from FluorSAIL canopy model

\begin{tabular}{lll}
\hline Parameter & Description & Units \\
\hline Esun & Solar irradiance on ground & $\mathrm{W} \mathrm{m}^{-2} \mu \mathrm{m}^{-1}$ \\
Esky & Sky irradiance on ground & $\mathrm{W} \mathrm{m}^{-2} \mu \mathrm{m}^{-1}$ \\
refrad & Reference radiance (without fluorescence) on ground level & $\mathrm{W} \mathrm{m}^{-2} \mu \mathrm{m}^{-1} \mathrm{sr}^{-1}$ \\
flurad & Fluorescence radiance on ground level & $\mathrm{W} \mathrm{m}^{-2} \mu \mathrm{m}^{-1} \mathrm{sr}^{-1}$ \\
totrad & Total radiance on ground level & $\mathrm{W} \mathrm{m}^{-2} \mu \mathrm{m}^{-1} \mathrm{sr}^{-1}$ \\
refref & Reference reflectance on ground (without fluorescence) & - \\
reftot & Total reflectance factor on ground (with fluorescence) & - \\
refSAIL & Reflectance factor computed analytically with 4SAIL model & - \\
refSAIL/refref & Ratio included for validation of numerical procedures & - \\
TOAref bare & TOA reference radiance for bare soil surroundings & $\mathrm{W} \mathrm{m}^{-2} \mu \mathrm{m}^{-1} \mathrm{sr}^{-1}$ \\
TOAtot bare & TOA total radiance for bare soil surroundings & $\mathrm{W} \mathrm{m}^{-2} \mu \mathrm{m}^{-1} \mathrm{sr}^{-1}$ \\
TOAref same & TOA reference radiance for surroundings same as target & $\mathrm{W} \mathrm{m}^{-2} \mu \mathrm{m}^{-1} \mathrm{sr}^{-1}$ \\
TOAtot same & TOA total radiance for surroundings same as target & $\mathrm{W} \mathrm{m}^{-2} \mu \mathrm{m}^{-1} \mathrm{sr}^{-1}$ \\
\hline
\end{tabular}

All spectral ranges in $400-1000 \mathrm{~nm}$.

TOAref bare, TOAtot bare, TOAref same, and TOAtot same will be calculated when input Vza and Raz are less than $2^{\circ}$ different than Vza and Raz used to generate atmospheric MEP file. 


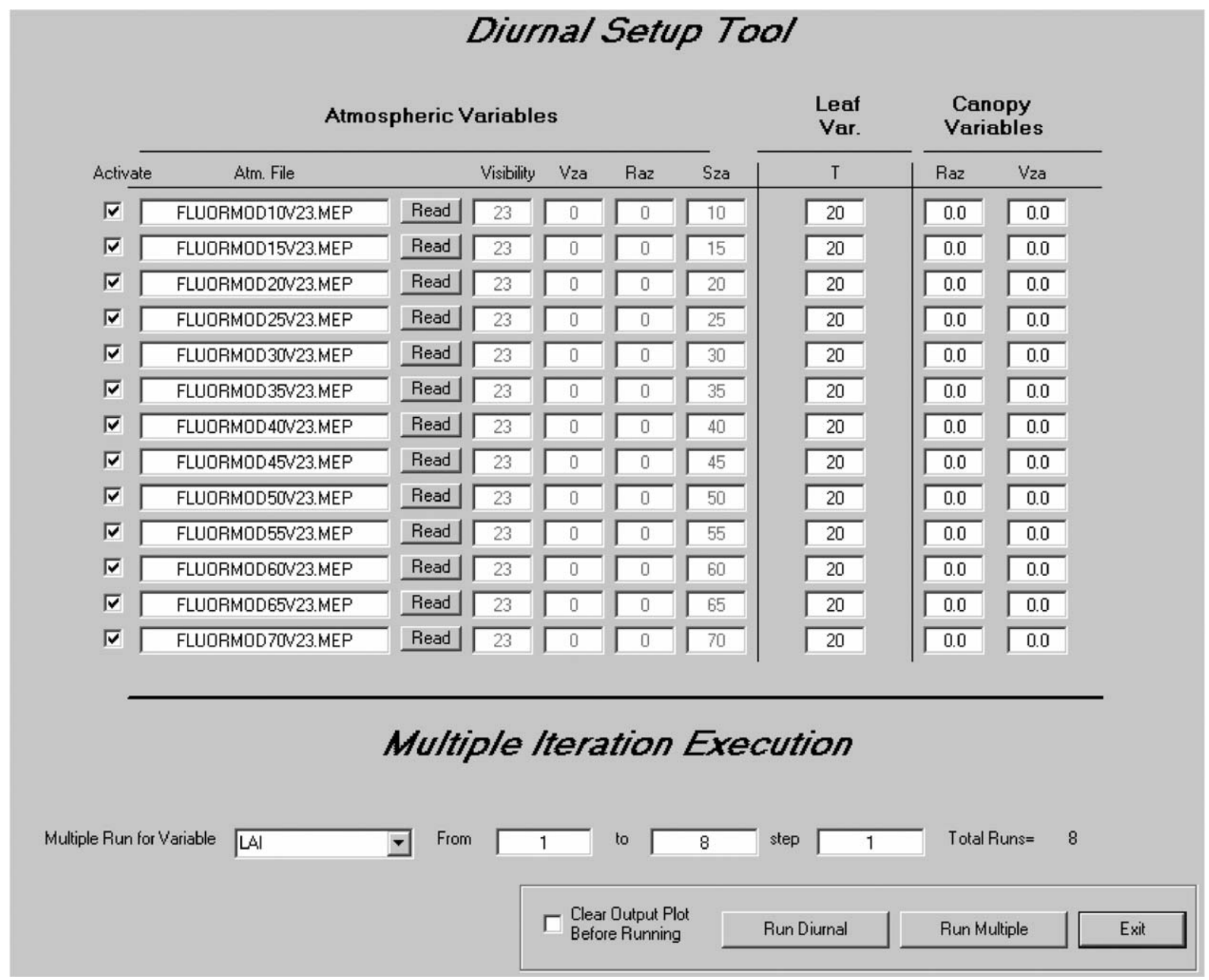

Fig. 5. View of diurnal setup and multiple iteration execution tools of FluorMODgui.

execution process for both the diurnal and multiple iteration can be cancelled at any time by the user.

\section{Simulation results with FluorMODgui}

The linked FluorMODleaf and FluorSAIL models through the FluorMODgui interface can now be used to simulate the spectral effects of the chlorophyll fluorescence at the leaf and canopy levels. The interface is provided to the user with a set of pre-calculated MODTRAN effective parameter files at $1 \mathrm{~nm}$ resolution for solar zenith angles ranging from $10^{\circ}$ to $70^{\circ}$ and $23 \mathrm{~km}$ visibility. The input parameters used to generate the set of MEP files from MODTRAN-4 are shown in Table 6.

To demonstrate the capabilities of the FluorMODgui model, a set of sample simulations were conducted for a range of input parameters. The simulation of upward and downward fluorescence emission spectra at the leaf level as a function of the chlorophyll concentration and quantum fluorescence efficiency are shown in Fig. 6. As expected, the spectral distribution of chlorophyll fluorescence shows that upward emission is greater than downward emission for both levels of chlorophyll concentrations (Fig. 6a, c for upward; Fig. 6b, d for downward emission). With increasing chlorophyll concentration from 30 to $80 \mu \mathrm{g} / \mathrm{cm}^{2}$, upward flux decreases slightly for the emission peak maximum centered at $685 \mathrm{~nm}$ (that mainly corresponds to PSII), with a slight increase of the peak maximum centered at $740 \mathrm{~nm}$ (that mainly corresponds to PSI) (Fig. 6a, c). On the other hand, the downward flux is highly affected by chlorophyll concentration levels 
Table 6

Input parameters used to generate MEP files from MODTRAN4 provided with interface

\begin{tabular}{ll}
\hline Parameter & Value \\
\hline Atmospheric profile & Mid-latitude summer \\
Use DISORT & Yes \\
Azimuth dependence & Yes \\
Number of streams & 4 \\
$\mathrm{CO}_{2}$ mixing ratio & $365 \mathrm{ppm}$ \\
Aerosol extinction model & Rural \\
Stratospheric aerosol & Background profile and \\
& extinction \\
Visibility & $23 \mathrm{~km}$ \\
Sensor altitude & $674 \mathrm{~km}$ \\
Target altitude & $0 \mathrm{~km}$ \\
Aerosol phase functions & Internal Mie-generated \\
Day of year & 162 \\
Spectral range & $400-1000 \mathrm{~nm}$ \\
Interval & $1 \mathrm{~nm}$ \\
FWHM & $1 \mathrm{~nm}$ \\
Slit function & Gaussian \\
\hline
\end{tabular}
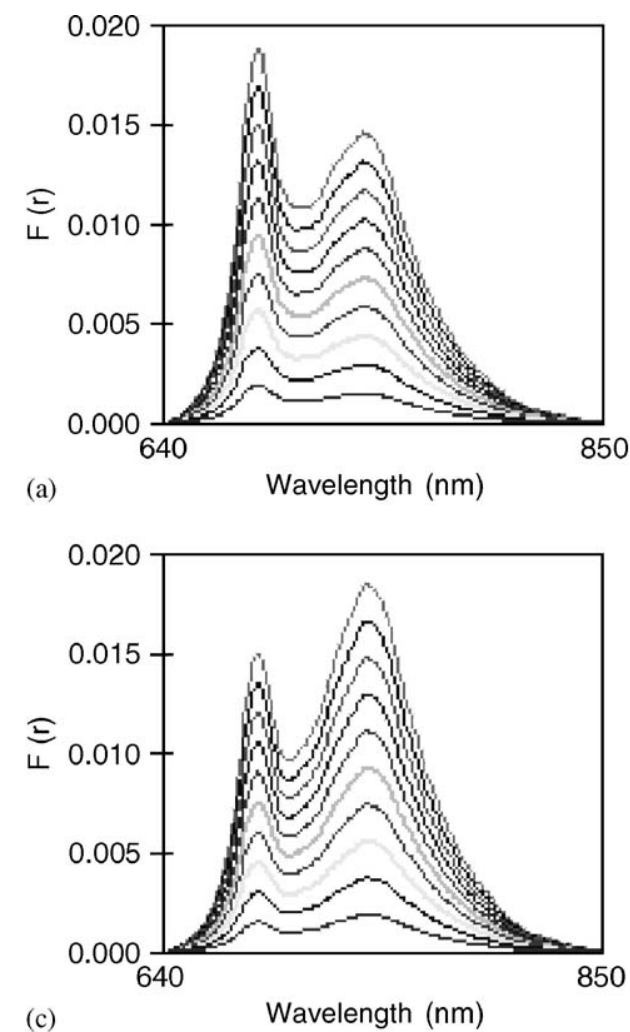

due to re-absorption effects, generating a substantial decrease in fluorescence emission at $685 \mathrm{~nm}$ in the downward flux when chlorophyll fluorescence is high (Fig. 6b, d).

The simulated upward and downward spectral fluorescence emission can then be used to generate the leaf reflectance and transmittance with and without the fluorescence effects. Fig. 7 shows the leaf reflectance (Fig. 7a, c) and transmittance (Fig. 7b, d) without $(\mathrm{Fi}=0)$ and with $(\mathrm{Fi}=0.04)$ fluorescence simulation for low chlorophyll concentration of $30 \mu \mathrm{g} / \mathrm{cm}^{2}$ (Fig. 7a, b) and high concentration of $80 \mu \mathrm{g} / \mathrm{cm}^{2}$ (Fig. 7c, d). The fluorescence spectra superimposed on top of the reflectance and transmittance can be observed along the red edge spectral region, and more specifically over the chlorophyll absorption maximum at $685 \mathrm{~nm}$ and on the reflectance shoulder at $740 \mathrm{~nm}$.

The outputs generated from the FluorMODleaf model simulating the spectral fluorescence signature
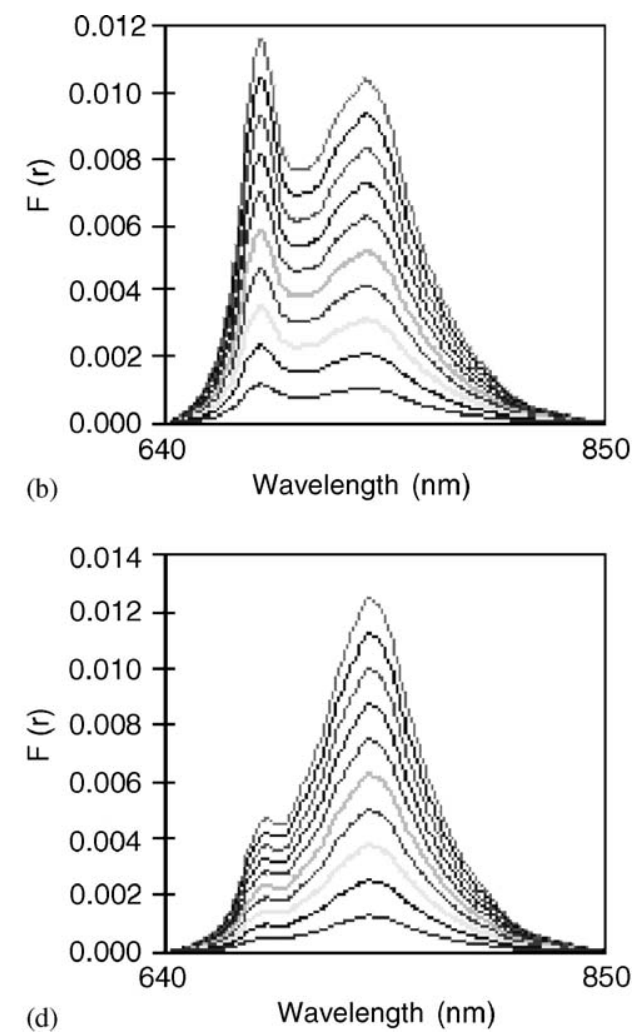

Fig. 6. Chlorophyll fluorescence emission spectra simulated with FluorMODgui in upward (a, c) and downward (b, d) direction for $C_{a b}=30 \mu \mathrm{g} / \mathrm{cm}^{2}$ (a, b) and $C_{a b}=80 \mu \mathrm{g} / \mathrm{cm}^{2}$ (c, d) for a range of fluorescence quantum efficiencies $(\mathrm{Fi}=0.001-0.1)$. Other input parameters used for simulation were $N=1.5, C_{\mathrm{w}}=0.025 \mathrm{~cm}, C_{\mathrm{m}}=0.01 \mathrm{~g} / \mathrm{cm}^{2}, T=20^{\circ} \mathrm{C}, S=2$, Sto $=2.0$, PAR $b=0.0035$, and $\mathrm{PAR}_{\mathrm{re}}=0.005$. 
and leaf reflectance and transmittance are then used as input for the FluorSAIL canopy model. This linked scheme simulates the radiance, reflectance and other parameters at the canopy level with and without the fluorescence effects for a range of inputs (Fig. 8). The effects of chlorophyll concentration for
$\mathrm{C}_{a b}$ ranging from 30 to $80 \mu \mathrm{g} / \mathrm{cm}^{2}$ (Fig. 8a) and leaf area index ranging from 1 to 7 (Fig. 8b) can be observed for a fixed set of other leaf and canopy parameters, enabling the quantification of such other parameters on the retrieval of fluorescence signature from canopy reflectance. As an example of such
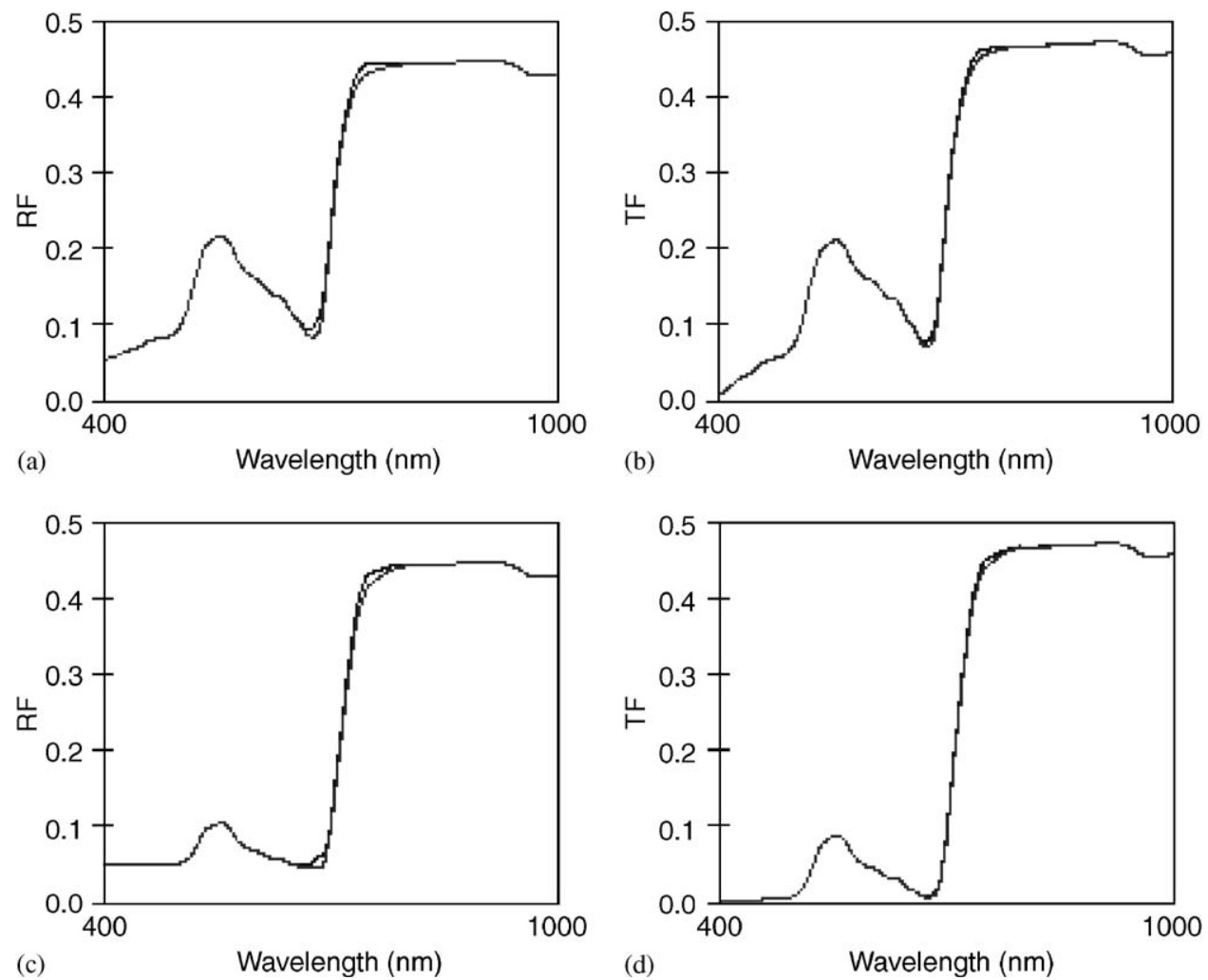

Fig. 7. FluorMODgui model simulation of leaf reflectance (a, c) and transmittance (b, d) for $C_{a b}=30 \mu \mathrm{g} / \mathrm{cm}^{2}(\mathrm{a}, \mathrm{b}) \mathrm{and} C_{a b}=80 \mu \mathrm{g} / \mathrm{cm}^{2}$ (c, d) with and without chlorophyll fluorescence effects.
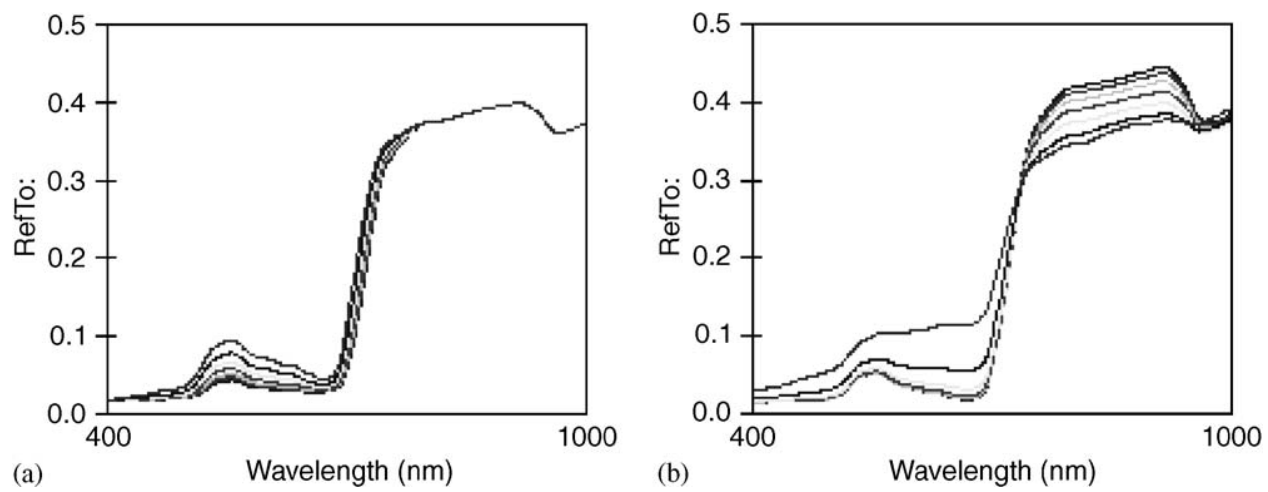

Fig. 8. Canopy reflectance (RefTot) simulation with FluorMODgui for a range of $C_{\mathrm{ab}}=30$ to $80 \mu \mathrm{g} / \mathrm{cm}^{2}$ and LAI $=4$ (a) and LAI $=1$ to 7 with $C_{a b}=30 \mu \mathrm{g} / \mathrm{cm}^{2}$ (b). Other input variables were $\mathrm{Fi}=0.04, T=5^{\circ} \mathrm{C}, N=1.5, C_{\mathrm{w}}=0.025 \mathrm{~cm}, C_{\mathrm{m}}=0.01 \mathrm{~g} / \mathrm{cm}^{2}, S=2, \mathrm{Sto}=2.0$, $\operatorname{PAR}_{b}=0.0035$, and $\mathrm{PAR}_{\mathrm{re}}=0.005$. 
fluorescence effects, canopy reflectance spectra were simulated with FluorMODgui for $C_{a b}=30 \mu \mathrm{g} / \mathrm{cm}^{2}$ (Fig. 9a, c, e) and $C_{a b}=80 \mu \mathrm{g} / \mathrm{cm}^{2}$ (Fig. 9b, d, f) showing the canopy reflectance with and without fluorescence addition. An emission peak at $761 \mathrm{~nm}$ can be observed in the apparent reflectance spectra due to the fluorescence in-filling effects at the oxygen band (Maier et al., 2003; Moya et al., 2004,
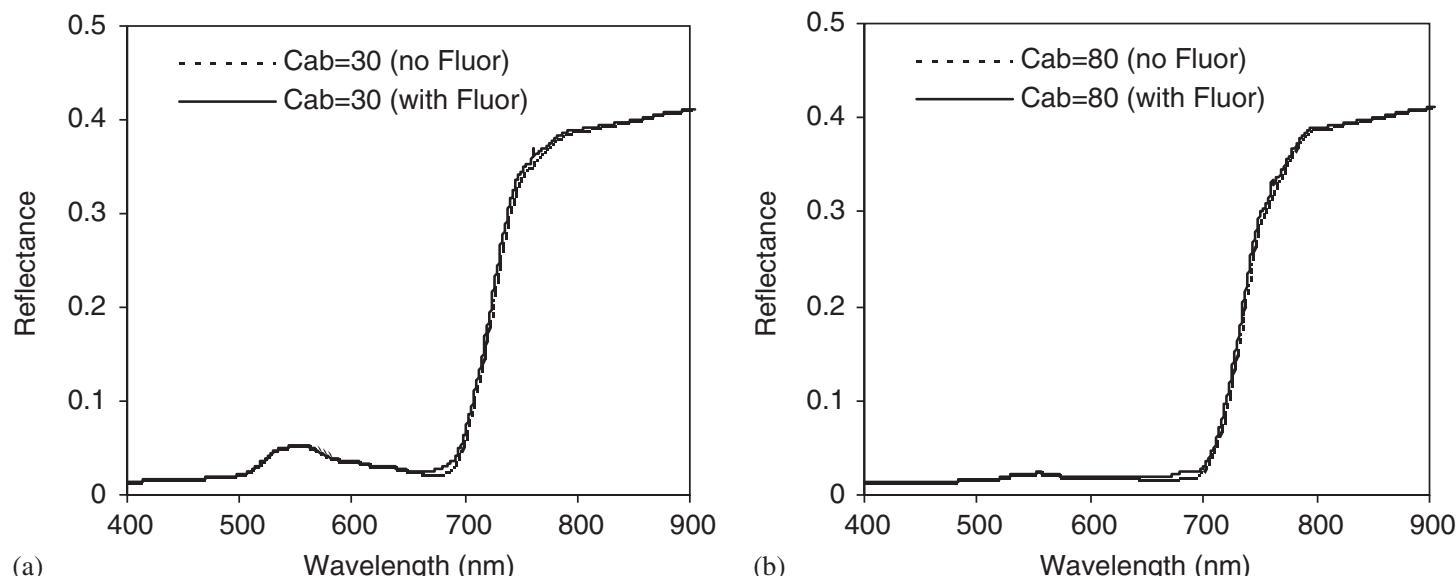

(b)

Wavelength $(\mathrm{nm})$
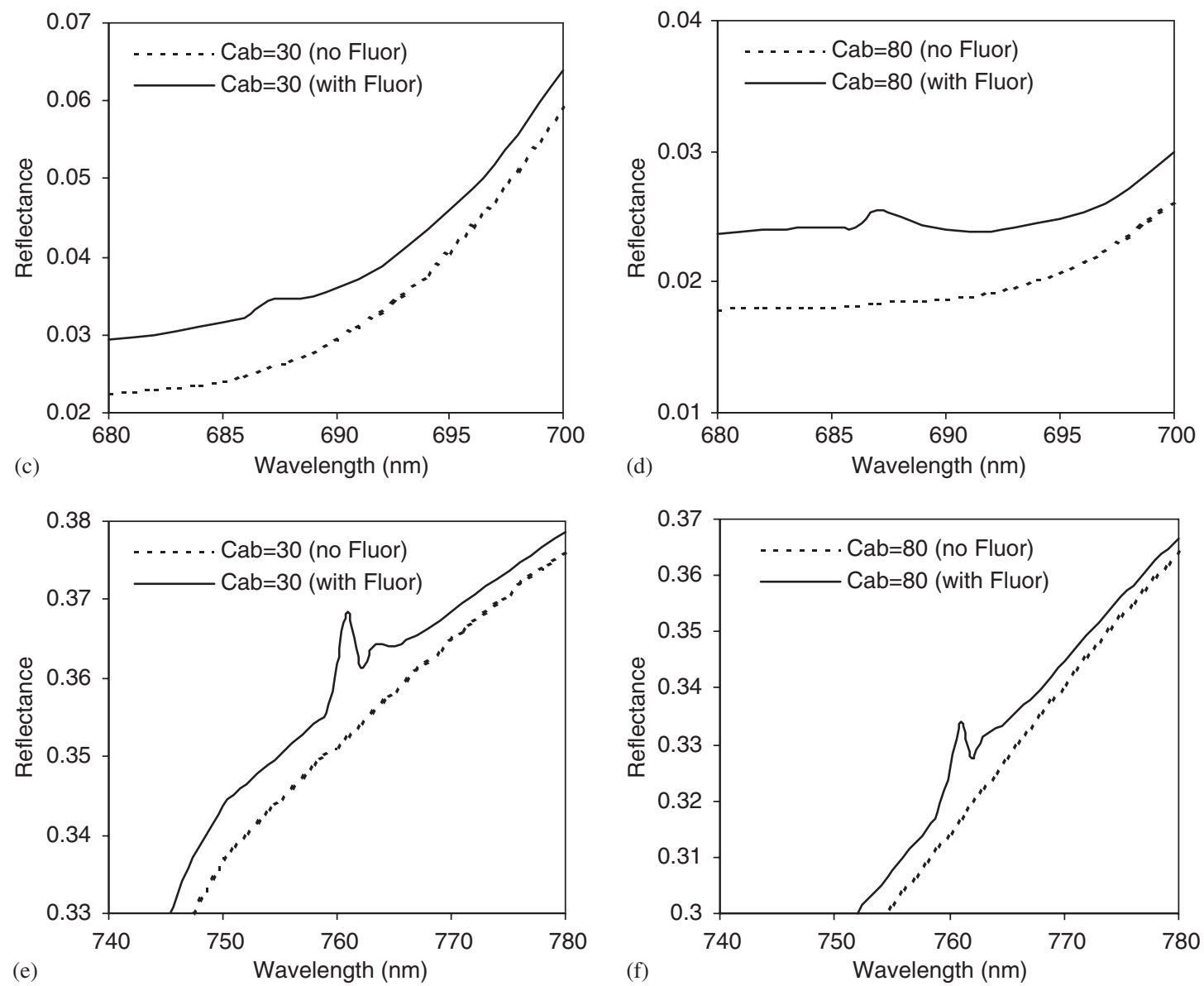

Fig. 9. Simulation of canopy reflectance for $C_{a b}=30 \mu \mathrm{g} / \mathrm{cm}^{2}$ (a, c, e) and $C_{\mathrm{ab}}=80 \mu \mathrm{g} / \mathrm{cm}^{2}$ (b, d, f) with (solid line) and without effects of chlorophyll fluorescence (dotted line). Other input variables were $\mathrm{Fi}=0.04, T=5{ }^{\circ} \mathrm{C}, N=1.5, C_{\mathrm{w}}=0.025 \mathrm{~cm}, C_{\mathrm{m}}=0.01 \mathrm{~g} / \mathrm{cm}^{2}, S=2$, Sto $=2.0, \mathrm{PAR}_{b}=0.0035, \mathrm{PAR}_{\mathrm{re}}=0.005, \mathrm{LAI}=4, \mathrm{Raz}$ and $\mathrm{Vza}=0^{\circ}, h=0.1$, and $\mathrm{LIDF}_{a}=\mathrm{LIDF}_{b}=-0.5$. 
Zarco-Tejada et al., 2003, 2005) (Fig. 9e, f), where for this simulation the input parameters used were: $\mathrm{Fi}=0.04, T=5{ }^{\circ} \mathrm{C}, N=1.5, C_{\mathrm{w}}=0.025 \mathrm{~cm}$, $C_{\mathrm{m}}=0.01 \mathrm{~g} / \mathrm{cm}^{2}, S=2$, Sto $=2.0, \mathrm{PAR}_{b}=0.0035$, $\mathrm{PAR}_{\mathrm{re}}=0.005, \mathrm{LAI}=4, \mathrm{Raz}$ and $\mathrm{Vza}=0, h=0.1$, and $\mathrm{LIDF}_{a}=\mathrm{LIDF}_{b}=-0.5$.

An example of the diurnal simulation using the Diurnal Simulation Tool can be seen in Fig. 10 for a number of spectral parameters obtained. The diurnal simulation was setup for a solar zenith angle ranging from $10^{\circ}$ to $70^{\circ}$, showing the simulation for solar irradiance (Fig. 10a); sky irradiance (Fig. 10b); total irradiance (Fig. 10c); radiance without fluorescence (Fig. 10d); fluorescence radiance (Fig. 10e); total radiance (Fig. 10f); reference reflectance (Fig. 10g); and total reflectance including fluorescence (Fig. 10h. Changes observed on the fluorescence emission simulated for a diurnal setting indicate that viewing angle effects should be seriously considered when retrieving the fluorescence signature from canopy reflectance under natural light conditions due to the effects caused by the sun angles for a fixed fluorescence quantum efficiency value (Fig. 10e).

This simulation tool with linked leaf and canopy models therefore enables the quantification of the fluorescence effects at the canopy level as a function of leaf, canopy and viewing and atmospheric/ illumination inputs. Further developments of the leaf and canopy models after future validations for calibration purposes will probably modify the absolute emission levels and other effects of the fluorescence spectra at both leaf and canopy models. Currently, the model is designed to simulate fluorescence effects for non-stress conditions.

\section{Conclusions}

The FluorMODgui V3.0 Graphic User Interface developed as part of the FluorMOD project Development of a Vegetation Fluorescence Canopy Model funded by ESA was presented in this manuscript. The FluorMODgui interface enables the simulation of leaf and canopy reflectance with the effects of chlorophyll fluorescence, running the leaf and canopy models FluorMODleaf and FluorSAIL independently and through a coupling scheme. The interface is designed to provide a link between the leaf and canopy models, with four main parts, a Menu Area for full control of the interface, an Irradiance File and PAR Dependence input area for controlling the light conditions and dependence, a Leaf Model Area for inputs and graphic outputs to run the FluoMODleaf model, and a Canopy Model Area for inputs and graphic outputs to run the FluorSAIL model.

The Leaf Input Parameters required to run FluorMODleaf are the number of layers, chlorophyll $\mathrm{a}+\mathrm{b}$, water equivalent thickness, dry matter content, fluorescence quantum efficiency, leaf temperature, species temperature dependence, and stoichiometry of PSII to PSI reaction centers. The outputs generated from FluoMODleaf fluorescence model are the leaf reflectance and transmittance without fluorescence, the leaf reflectance and transmittance with fluorescence, the fluorescence emission at the leaf level, and two matrices containing the upward and downward fluorescence.

The outputs from FluorMODleaf are used as inputs for FluorSAIL along with the viewing zenith and relative azimuth angles, the canopy leaf area index, the hot spot parameter, the leaf inclination distribution function parameters, and a soil spectrum file. Outputs from FluorSAIL contain the solar irradiance, sky irradiance, total irradiance, radiance without fluorescence, fluorescence radiance, total radiance, reference reflectance, total reflectance, reflectance as in SAIL, the ratio SAIL/ FluorSAIL, and reference and total top-of-atmosphere radiances.

The Graphic User Interface facilitates multiple runs with varying leaf and canopy variables, generating the model results in plots and enabling the output data to be saved in text files for further analysis. A Diurnal and Multiple Iteration Tool is presented which facilitates the user's simulation of the diurnal effects of fluorescence as function of variables that typically change in a diurnal setting. A set of pre-calculated atmospheric files to simulate the typical range of atmospheric conditions for different sun viewing angles and a standard $23 \mathrm{~km}$ visibility atmosphere is made available with the graphic user interface. Other simulated atmospheric conditions can be calculated with MODTRAN-4 and used as user-defined input for FluorMODgui.

It is expected that the FluorMODgui interface will be used as a tool for leaf and canopy model validation through the use of existing and future field datasets under the frame of this ESA project and for the interested scientific community. Ongoing research will improve FluorMODleaf, FluorSAIL and FluorMODgui graphic interface with current validation efforts being conducted. The upto-date models, graphic interface version, and 

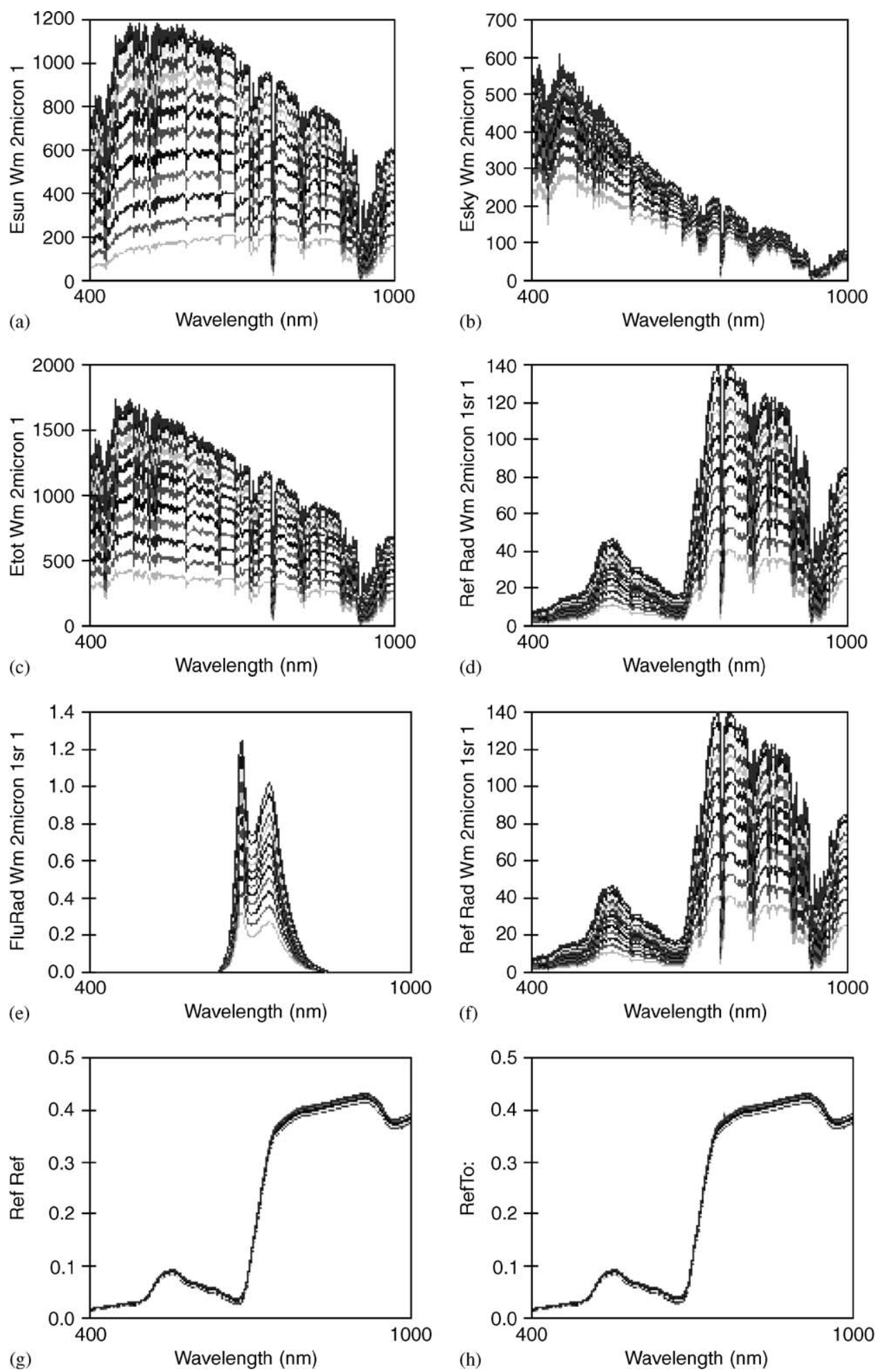

Fig. 10. Diurnal simulation with FluorMODgui for a solar zenith angle ranging from $10^{\circ}$ to $70^{\circ}$ obtaining solar irradiance (a); sky irradiance (b); total irradiance (c); radiance without fluorescence (d); fluorescence radiance (e); total radiance (f); reference reflectance (g); and total reflectance including fluorescence (h). 
documentation can be obtained by interested collaborators from a dedicated web page at http:// www.ias.csic.es/fluormod.

\section{Acknowledgements}

The development of the FluorMODgui interface has been made possible by the funding support of the ESA-project Development of a Vegetation Fluorescence Canopy Model, through the ESTEC contract no. 16365/02/NL/FF. Through this project and additional contributions, the leaf and canopy fluorescence models FluorMODleaf and FluorSAIL were developed and provided by R. Pedrós and S. Jacquemoud of LED Laboratory, University of Paris 7, I. Moya, Y. Goulas and J. Louis of LURE Laboratory, National Centre for Scientific Research CNRS, and W. Verhoef, National Aerospace Laboratory NLR. Computer and web page support contributions of M.L. Muñoz-Urbano from IAS-CSIC are acknowledged.

\section{References}

Agati, G., 1998. Response of the in vivo chlorophyll fluorescence spectrum to environmental factors and laser excitation wavelength. Pure and Applied Optics 7, 797-807.

Berk, A., Anderson, G.P., Acharya, P.K., Chetwynd, J.H., Hoke, M.L., Bernstein, L.S., Shettle, E.P., Matthew, M.W., AdlerGolden, S.M., 1999. MODTRAN4 Version 2 User's Manual. AFRL, Space Vehicles Directorate, Hanscom AFB, MA 01731-3010.

Jacquemoud, S., Baret, F., 1990. Prospect: a model for leaf optical properties spectra. Remote Sensing of the Environment 34, 75-91.

Maier, S.W., 2000. Modeling the radiative transfer in leaves in the $300 \mathrm{~nm}$ to $2.5 \mu \mathrm{m}$ wavelength region taking into consideration chlorophyll fluorescence-the leaf model SLOPE. Ph.D. Dissertation, Technische Universität München, München, Germany, 124pp.

Maier, S.W., Gunther, K.P., Stellmes, M., 2003. Sun-induced fluorescence: a new tool for precision farming. In: McDonald, M., Schepers, J., Tartly, L., VanToai, T., Major, D. (Eds.), Digital Imaging and Spectral Techniques. Applications to Precision Farming and Crop Physiology. American Society of Agronomy, Special Publication 66, pp. 209-222.
Maier, S.W., Lüdeker, W., Günther, K.P., 1999. SLOP: a revised version of the stochastic model for leaf optical properties. Remote Sensing of the Environment 68 (3), 273-280.

Miller, J.R., Berger, M., Alonso, L., Cerovic, Z., Goulas, Y., Jacquemoud, S., Louis, J., Mohammed, G., Moya, I., Pedros, R., Moreno, J., Verhoef, W., Zarco-Tejada, P.J., 2004. Progress on the development of an integrated canopy fluorescence model, 2003. In: International Geoscience and Remote Sensing Symposium, IGARSS'03, vol. 1, Toulouse, France, pp. 601-603, ISBN 0-7803-79292-0-7803-7930-6.

Moya, I., Camenen, L., Evain, S., Goulas, Y., Cerovic, Z.G., Latouche, G., Flexas, J., Ounis, A., 2004. A new instrument for passive remote sensing. 1. measurements of sunlightinduced chlorophyll fluorescence. Remote Sensing of Environment 91 (2), 186-197.

Pedrós, R., Jacquemoud, S., Goulas, Y., Louis, J., Moya, I., 2005. A new leaf fluorescence model. In: Second International Workshop on Remote Sensing of Vegetation Fluorescence, 17-19 November 2004, Montreal, Canada.

Rosema, A., Snel, J.F.H., Zahn, H., Buurmeijer, W.F., van Hove, L.W.A., 1998. The relation between laser induced chlorophyll fluorescence and photosynthesis. Remote Sensing of Environment $65,143-154$.

Verhoef, W., 1984. Light scattering by leaf layers with application to canopy reflectance modeling: the SAIL model. Remote Sensing of the Environment 16, 125-141.

Verhoef, W., 1998. Theory of radiative transfer models applied in optical remote sensing of vegetation canopies. Ph.D. Dissertation, Wageningen Agricultural University, Wageningen, The Netherlands, 310pp.

Verhoef, W., 2005. Extension of SAIL to model solar-induced canopy fluorescence spectra. In: Second International Workshop on Remote Sensing of Vegetation Fluorescence, 17-19 November 2004, Montreal, Canada.

Zarco-Tejada, P.J., Miller, J.R., Mohammed, G.H., Noland, T.L., 2000. Chlorophyll fluorescence effects on vegetation apparent reflectance: I. Leaf-level measurements and model simulation. Remote Sensing of Environment. 74 (3), 582-595.

Zarco-Tejada, P.J., Miller, J.R., Haboudane, D., Tremblay, N., Apostol, S., 2003. Detection of chlorophyll fluorescence in vegetation from airborne hyperspectral CASI imagery in the red edge spectral region, 2003. In: International Geoscience and Remote Sensing Symposium, IGARSS'03, 21-25 July 2003, Toulouse, France vol. 1, pp. 598-600, ISBN 0-78037929-2-0-7803-7930-6.

Zarco-Tejada, P.J., Pérez-Priego, O., Sepulcre-Cantó, G., Miller, J.R., Fereres, E., 2005. Chlorophyll fluorescence detection with a high-spectral resolution spectrometer through in-filling of the $\mathrm{O}_{2}-\mathrm{A}$ band as function of water stress in olive trees. In: Second International Workshop on Remote Sensing of Vegetation Fluorescence, 17-19 November 2004, Montreal, Canada. 